American Journal of Applied Sciences 9 (9): 1464-1471, 2012

ISSN 1546-9239

(C) 2012 Science Publication

\title{
Design and Development of an Intelligent Control by Using Bee Colony Optimization Technique
}

\author{
S. Tiacharoen and T. Chatchanayuenyong \\ Faculty of Engineering, Mahasarakham University, \\ T. Khamriang, A. Kantarawichai, Mahasarakham, 44150, Thailand
}

\begin{abstract}
Problem statement: In the modern industrial manufacturing system, the efficiency of machine control is essential to reduce waste and increase the output. Most of the manufacturing machines employ an induction motor in their driving system. A number of induction motors must be controlled during machine operation. The more accurately these motors are controlled the higher is the quality of the finished product. Approach: This study focuses on using the Bee Colony Optimization (BCO) to find optimal fuzzy rules and membership functions of a fuzzy speed controller for an indirect field-orientated Induction Motor (IM). The BCO optimizes those quantities so that the controller can control the motor to a desired speed with the minimum rise time and speed error. The fitness function of BCO is defined as rise time and Integral Time Absolute Error (ITAE). An indirect field-orientation method for an IM drive and a description of the BCO are introduced briefly. Results: The speed tracking capability of the Proportional-Integral (PI), fuzzy and BCO optimized fuzzy controllers are compared under no-load and various load conditions with different reference speeds. Conclusion: The designed controller could track to the set point with a relatively minimum rise time and low overshoot compared to the other conventional controllers.
\end{abstract}

Key words: Bee Colony Optimization (BCO), Induction Motor (IM), Integral Time Absolute Error (ITAE), speed tracking capability, conventional controllers, induction motor

\section{INTRODUCTION}

Manufacture of the industry components consumes resources such as materials, capital, time and energy. The manufacturing process outputs are in the form of product and waste materials. To reduce the waste, a number of process parameters must be controlled during machine operation, particularly those determining the rate of material removal. The more accurately these parameters are controlled the higher is the quality of the finished product (Waters, 1996). Automatic control has become an important and integral part of modern manufacturing and industrial processes (Ogata, 1996). For example, automatic control is essential in the numerical control of machine tool in the manufacturing industries, in the design of cars and truck in the automobile industries and in the design of aircraft parts in the aerospace industries (My et al., 2005). In process measurement and control of machine tool accuracy while increasing productivity and reduce waste (Feng et al., 2003). In a machine tool, motion (position and speed) control of the axes is necessary (Esawi and Ashby, 2003). In a turning operation, the cutting speed is directly related to the spindle speed. That relates to speed controller of spindle motor. In the manufacturing process mentioned above, the alternating current asynchronous motors or induction motors are often the preferred choice in industrial drive applications (Vas, 1999). In order to achieve the performance required by industrial drive application, these induction motors have to be controlled effectively.

Fuzzy logic controller was based on the fuzzy sets theory of (Zadeh, 1965). The fuzzy logic controller consists of three parts; Fuzzification of input parameters, Inference Engine and Defuzzification of output parameter. The major problems to implement the fuzzy logic controller are the determination of the definition of the membership functions and linguistic state space of the controller rules, of which the optimal solution is always based on the human experience and time-consuming trial-and-error process. A number of optimization techniques in the literature have been employed to solve this problem. Among of these techniques are Genetic Algorithm (Jurado and Valverde, 2005), Tabu Search Algorithm (Lee, 2005),

Corresponding Author: Chatchanayuenyong, T., Faculty of Engineering, Mahasarakham University, T. Khamriang, A. Kantarawichai, Mahasarakham, 44150, Thailand Tel: +6643754322 Ext.3004 Fax: +6643754316 
Particle Swarm Optimization (Karakuzu, 2010) and the Ant Colony Optimization (Abadeh et al., 2008).

This study focuses on using a new optimization technique called the Bee Colony Optimization (BCO) to find the optimal fuzzy rules and membership functions of a fuzzy speed controller for an indirect field-orientated Induction Motor (IM). The term intelligence is defined as the ability to make the right decision (Jones, 2007) of human or bio-systems. By this definition, the BCO, which mimics the honey foraging behavior of bees (Pham et al., 2006) and use mechanisms such as waggle move to optimally locate honey sources and to find new source could be a choice of intelligence control system. The BCO is very simple, robust and population based stochastic optimization algorithm.

The remaining of the study is organized as follows. Materials and methods explains the indirect field-oriented control for the induction motor, a general view of fuzzy logic controller and Bee Colony Optimization algorithm. Results addresses the procedure to implement the proposed algorithm for the indirect field-oriented control and its corresponding simulation results. Discuusion and Conclusion provides the result discussion and some concluding remarks respectively.

\section{MATERIALS AND METHODS}

Indirect field-oriented control: In a field-oriented controller, the magnitude and phase of each phase current and voltage must be controlled, in corresponding to changes in both the speed and the torque load. Field-oriented control can be done by using either the direct (Blaschke, 1972) or the indirect control method. The indirect field-oriented control method uses motor's parameters and rotational-position measurement to generate unit vector signals for the transformation in feed forward path. The field-oriented controller accepts the torque and flux command and then generates the torque and flux-producing components of the stator-current and the slip-angle, $\theta_{\mathrm{s}}^{*}$, commands. The slip angle command $\theta_{\mathrm{S}}^{*}$ is generated by integrating, $\omega_{\mathrm{S}}^{*}$ (the slip speed) as given in Eq. 1:

$$
\theta_{\mathrm{s}}^{*}=\int \omega_{\mathrm{s}}^{*} \mathrm{dt}
$$

The angle between the stator current components, $i_{\mathrm{T}}^{*}$ and $i_{\mathrm{f}}^{*}$ gives the torque-angle command. The fluxand torque-producing components of the stator-current commands are obtained as shown in Eq. 2-3:

$$
\mathrm{i}_{\mathrm{T}}^{*}=\frac{\mathrm{T}_{\mathrm{e}}^{*}}{\lambda_{\mathrm{r}}^{*} \mathrm{~K}_{\mathrm{te}}}
$$

$$
\mathrm{i}_{\mathrm{f}}^{*}=\frac{\lambda_{\mathrm{r}}^{*}}{\mathrm{~L}_{\mathrm{m}}^{*}}\left(1+\mathrm{T}_{\mathrm{r}}^{*} \mathrm{p}\right)
$$

where, slip speed, $\omega_{\mathrm{S}}^{*}$ is given in Eq. 4:

$$
\omega_{\mathrm{s}}^{*}=\frac{\mathrm{i}_{\mathrm{T}}^{*} \mathrm{~L}_{\mathrm{m}}^{*}}{\lambda_{\mathrm{r}}^{*} \mathrm{~T}_{\mathrm{r}}^{*}}=\mathrm{K}_{\mathrm{it}} \mathrm{R}_{\mathrm{r}}^{*} \frac{\mathrm{T}_{\mathrm{e}}}{\left(\lambda_{\mathrm{r}}^{*}\right)^{2}}
$$

Where

$$
\mathrm{K}_{\mathrm{it}}=\frac{2}{3 \mathrm{P}}
$$

And

$$
\mathrm{K}_{\mathrm{te}}=\frac{3}{2} \frac{\mathrm{P}}{2} \frac{\mathrm{L}_{\mathrm{m}}}{\mathrm{L}_{\mathrm{r}}}
$$

$\mathrm{R}_{\mathrm{r}}^{*}=$ Rotor resistance

$\mathrm{T}_{\mathrm{e}}^{*}=$ Electromagnetic torques

$\mathrm{P}=$ Pairs of poles

$\mathrm{T}_{\mathrm{r}}^{*}=$ Rotor time constant

$\lambda_{\mathrm{r}}^{*}=$ Flux linkages in the stator reference frame

The field angle $\left(\theta_{\mathrm{f}}\right)$ is obtained by summing the slip angle command $\left(\theta_{\mathrm{s}}\right)$ with the rotor angle $\left(\theta_{\mathrm{r}}\right)$ as given in Eq. 5:

$\theta_{\mathrm{f}}=\theta_{\mathrm{r}}+\theta_{\mathrm{s}}$

With the torque and flux producing components of the stator-current command and rotor field angle, the $\mathrm{dq}$ axes current commands are obtained as shown in Eq. 6-7:

$$
\left[\begin{array}{l}
i_{d s}^{*} \\
i_{q s}^{*}
\end{array}\right]=\left[\begin{array}{cc}
\cos \theta_{f} & \sin \theta_{f} \\
-\sin \theta_{f} & \cos \theta_{f}
\end{array}\right] \quad\left[\begin{array}{l}
i_{T}^{*} \\
i_{f}^{*}
\end{array}\right]
$$

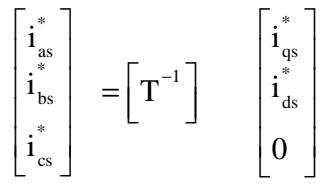




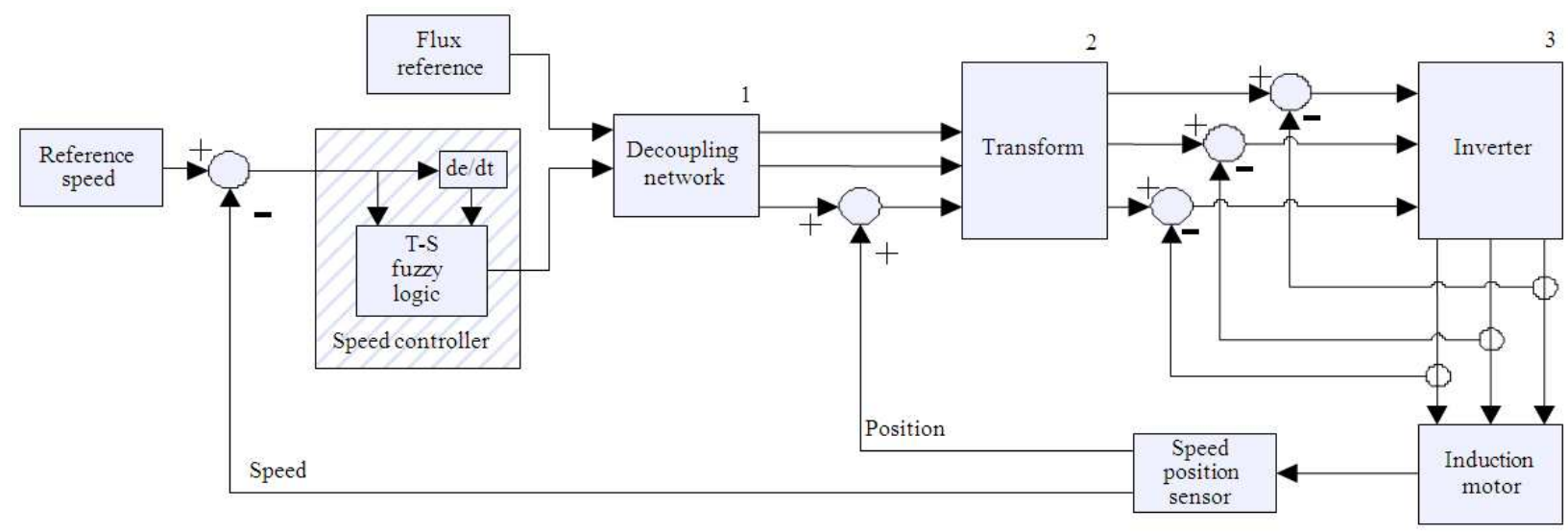

Fig. 1: Block diagram of the indirect field-oriented control system

Where:

$$
\mathrm{T}^{-1}=\left[\begin{array}{ccc}
1 & 0 & 1 \\
-1 / 2 & -\sqrt{3} / 2 & 1 \\
-1 / 2 & -\sqrt{3} / 2 & 1
\end{array}\right]
$$

$\mathrm{i}_{\mathrm{ds}}^{*}, \mathrm{i}_{\mathrm{qs}}^{*}=\mathrm{d}$, q-axis stator current components

$\mathrm{i}_{\mathrm{as}}^{*}, \mathrm{i}_{\mathrm{bs}}^{*}, \mathrm{i}_{\mathrm{cs}}^{*}=$ Are the torque component of the stator current

Then by computing stator current commands using $\mathrm{T}^{-1}$ current equations are obtained as shown in Eq. 8-12:

$\mathrm{i}_{\mathrm{qs}}^{*}=\left|\mathrm{i}_{\mathrm{s}}^{*}\right| \sin \theta_{\mathrm{s}}^{*}$

$\mathrm{i}_{\mathrm{ds}}^{*}=\left|\mathrm{i}_{\mathrm{s}}^{*}\right| \cos \theta_{\mathrm{s}}^{*}$

$\mathrm{i}_{\text {as }}^{*}=\left|\mathrm{i}_{\mathrm{s}}^{*}\right| \sin \theta_{\mathrm{s}}^{*}$

$\mathrm{i}_{\mathrm{bs}}^{*}=\left|\mathrm{i}_{\mathrm{s}}^{*}\right| \sin \left(\theta_{\mathrm{s}}^{*}-\frac{2}{3} \pi\right)$

$\mathrm{i}_{\mathrm{cs}}^{*}=\left|\mathrm{i}_{\mathrm{s}}^{*}\right| \sin \left(\theta_{\mathrm{s}}^{*}+\frac{2}{3} \pi\right)$

The proposed controller is shown in Fig. 1.

The first block in Fig. 1 calculates current and flux in d-q axes (Boldea and Nasar, 2006). The current controller should also ensure an ideal decoupling between the field and torque forming $i_{\mathrm{ds}}$ and $\mathrm{i}_{\mathrm{qs}}$ components since both components are strongly coupled to each other in the field synchronous coordinate system. The second block in Fig. 1, find a Park's transformation (Krause et al., 1995) of motor. The motor parameters are shown in Table 1.
Table 1: Induction motor parameters

\begin{tabular}{lll}
\hline Parameters & & Value \\
\hline $\mathrm{P}_{\mathrm{n}}$ & Nominal power & $1100 \mathrm{~W}$ \\
$\mathrm{~V}_{\mathrm{nf}}$ & Voltage & $220 \mathrm{~V}$ \\
$\mathrm{R}_{\mathrm{s}}$ & Stator resistance & $9.53 \mathrm{ohm}$ \\
$\mathrm{L}_{\mathrm{sc}}$ & Stator leakage inductance & $0.136 \mathrm{H}$ \\
$\mathrm{L}_{\mathrm{r}}$ & Rotor inductance & $0.0505 \mathrm{H}$ \\
$\mathrm{L}_{\mathrm{m}}$ & Mutual inductance & $0.447 \mathrm{H}$ \\
$\mathrm{J}$ & Rotor inertia & $0.0026 \mathrm{kgfm}^{2}$ \\
\hline
\end{tabular}

Fuzzy controller: The inputs of the fuzzy logic controller are an error between reference and feedback speed of the system. The fuzzy logic controller is designed as a multi-input and singleoutput control system. The inputs of the controller are speed error and speed error rate. The output of the fuzzy logic controller is a control action, u. The design procedures are as the followings. First, the membership function of inputs and output parameters were defined for both the input error and error rate, which consists of seven membership functions (mf1, $\mathrm{mf} 2, \ldots, \mathrm{mf} 7)$. The membership functions for the output start with seven membership functions $(\mathrm{mf} 1, \mathrm{mf} 2, \ldots$, mf7), which can be defined as the population of the BCO in its algorithm. Secondly, the rules table is used to analyze the output (control actions). There are 49 total numbers of fuzzy rules. Finally, the defuzzification was done by using the Center of Area (COA) methods as shown in Eq. 13:

COA $: \mathrm{u}_{\text {crisp }}(s)=\frac{\sum_{\mathrm{i}=1}^{\mathrm{m}} \mathrm{w}_{\mathrm{i}} \times \alpha_{\mathrm{i}}}{\sum_{\mathrm{i}=1}^{\mathrm{m}} \mathrm{w}_{\mathrm{i}}}$

where, the output level $a_{i}$ of each rule is weighted by the firing strength $\mathrm{w}_{\mathrm{i}}$ of the $\mathrm{i}^{\text {th }}$ rule. 
Bee cololny optimization: In BCO algorithm, the hive of artificial bees contains two groups of bees, which are scout and employed bees. The scout bees have the responsibility of finding a new honey source. The responsibility of employed bees is to determine a honey source within the neighborhood of the honey source in their memories and share their information with other bees within the hive. The procedure of the $\mathrm{BCO}$ algorithm is given as follows:

Step 1: Randomly generate the initial populations of scout bees

Step 2: Find the fitness value of the initial populations

Step 3: Neighborhood search: select the best sites and separate into two groups then find the size of patch sites

Step 4: Recruit employed bees for selected sites and select the fittest bees from each patch

Step 5: Check the stop criterion. If the criterion is satisfied, terminate the search

Step 6: Assign the remaining bees to random search and then go to Step 2

\section{RESULTS}

In the design process, the fuzzy logic controller based on T-S fuzzy logic consists of three parameters with two-input and one-output. Each parameter consists of two trapezoidal and five triangular membership functions. The control rules are shown in Table 2 and its corresponding graphs are shown in Fig. 2. These membership functions and control rules are automatically tuned by the BCO.

Parameters in Table 3 were employed in the BCO optimization process.

The performance index in the optimization algorithm of BCO is the Integral Time Absolute Error
(ITAE) of speed error and rise time. As a consequence, $F$, the objective function, is defined by Eq. 14:

$\operatorname{Minimize} F=\int($ error $) d t+t_{r}$

As a result, the tuned parameters of memberships of fuzzy logic controllers are illustrated in Fig. 3

The simulation results are shown in Fig. 4 and 5. They depict the speed and torque responses for starting transience at speed set point of $120 \mathrm{rad} / \mathrm{s}$, while a load disturbance applied at $\mathrm{t}=0.4 \mathrm{sec}$. Figure 4 shows a comparison between Proportional-Integral (PI) controller and optimized fuzzy logic controller under no-load and load condition. The integral gain $\left(\mathrm{K}_{\mathrm{i}}\right)$ and the integral time $\left(\mathrm{T}_{\mathrm{i}}\right)$ of the PI controllers were set to 10 and $0.8 \mathrm{~s}$ respectively. Figure 5 depicts torque response comparison between both controllers.

Table 2: Control rules of fuzzy logic controller

\begin{tabular}{llllllll}
\hline & \multicolumn{2}{l}{ Error } & & & & & \\
Error rate & LN & MN & SN & Z & SP & MP & LP \\
\hline LN & LP & LP & LP & MP & MP & SP & Z \\
MN & LP & MP & MP & MP & SP & Z & SN \\
SN & LP & MP & SP & SP & Z & SN & MN \\
Z & MP & MP & SP & Z & SN & MN & MN \\
SP & MP & SP & Z & SN & SN & MN & LP \\
MP & SP & Z & SN & MN & MN & MN & LP \\
LP & Z & SN & MN & MN & LP & LP & LP \\
\hline
\end{tabular}

Table 3: Parameters setting of the BCO

\begin{tabular}{llr}
\hline Bees algorithm parameters & Symbol & Value/range \\
\hline Population & $\mathrm{n}$ & 10.00 \\
Number of selected sites & $\mathrm{m}$ & 5.00 \\
Number of elite site & $\mathrm{e}$ & 2.00 \\
Patch size & $\mathrm{ngh}$ & 0.01 \\
Number of bees around elite site & nep & 5.00 \\
Number of bees around other selected site & $\mathrm{nsp}$ & 2.00 \\
Maximum number of iteration & itermax & 100.00
\end{tabular}

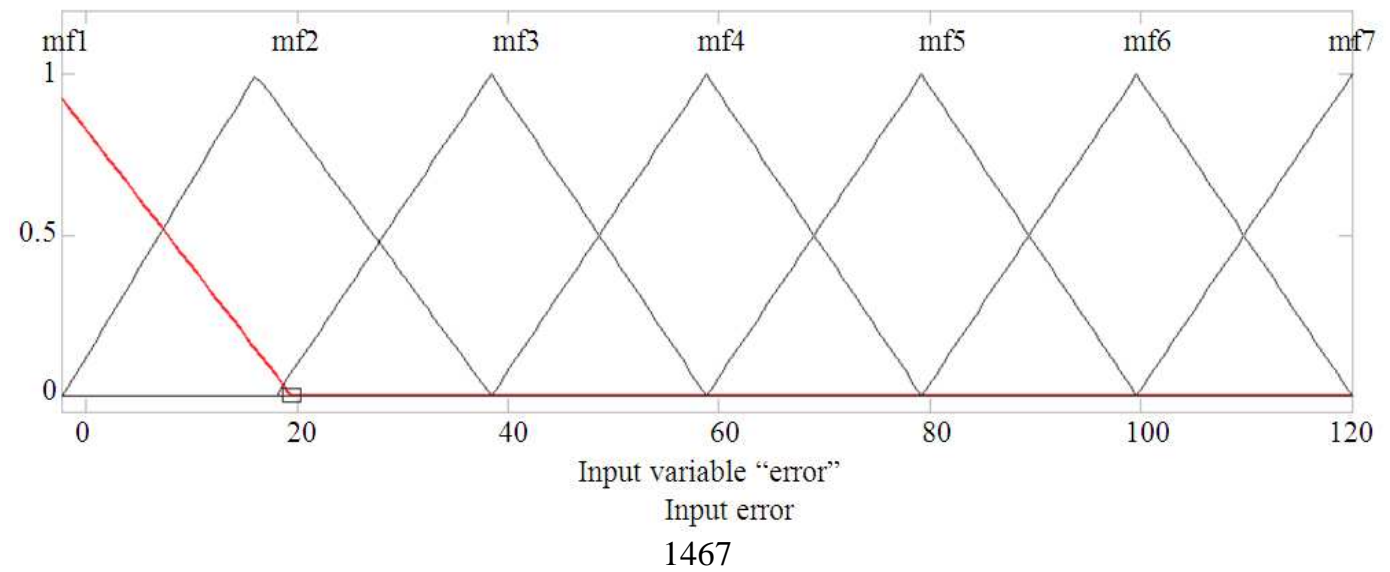


Am. J. Applied Sci., 9 (9): 1464-1471, 2012
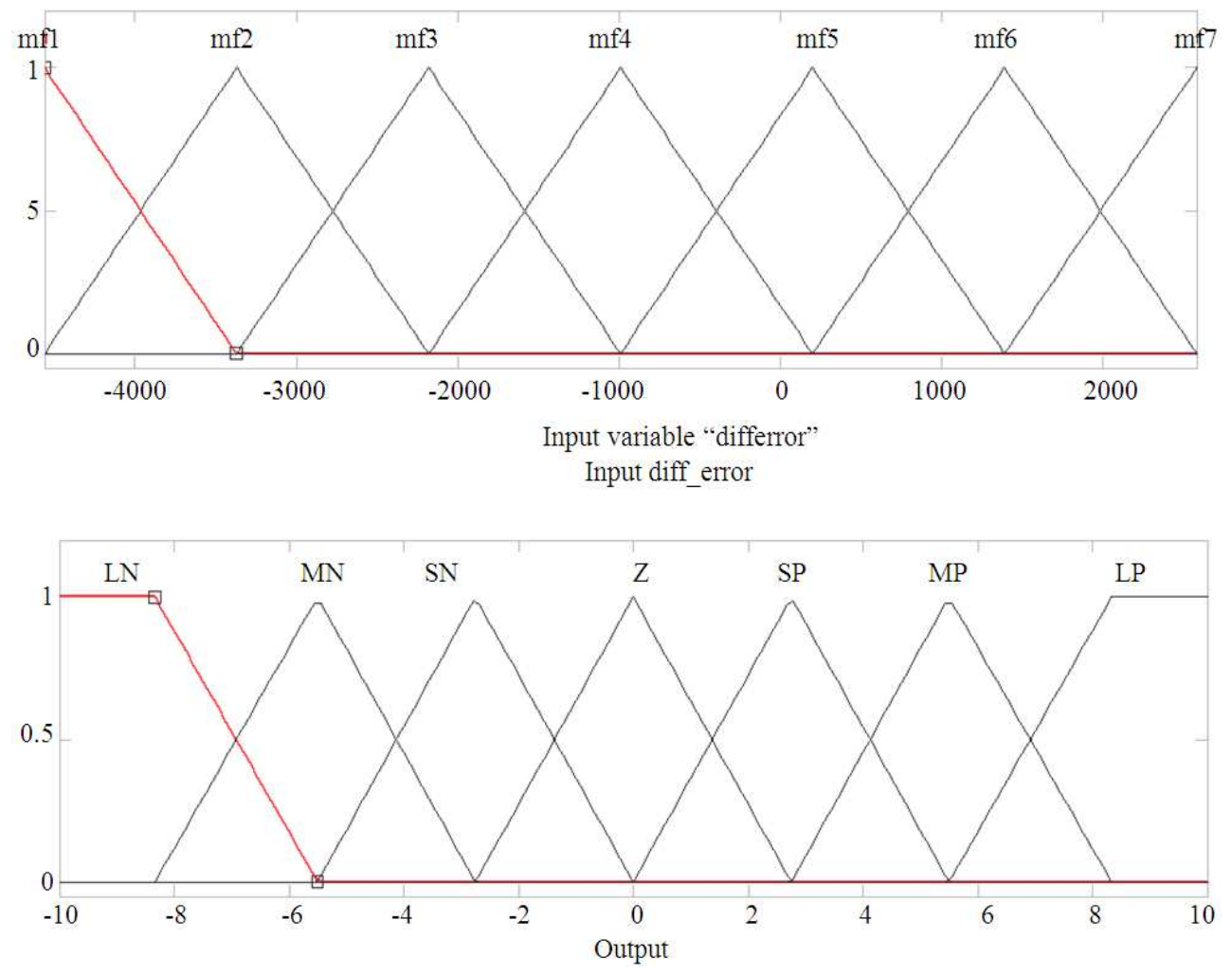

Fig. 2: Membership functions of the fuzzy logic controller
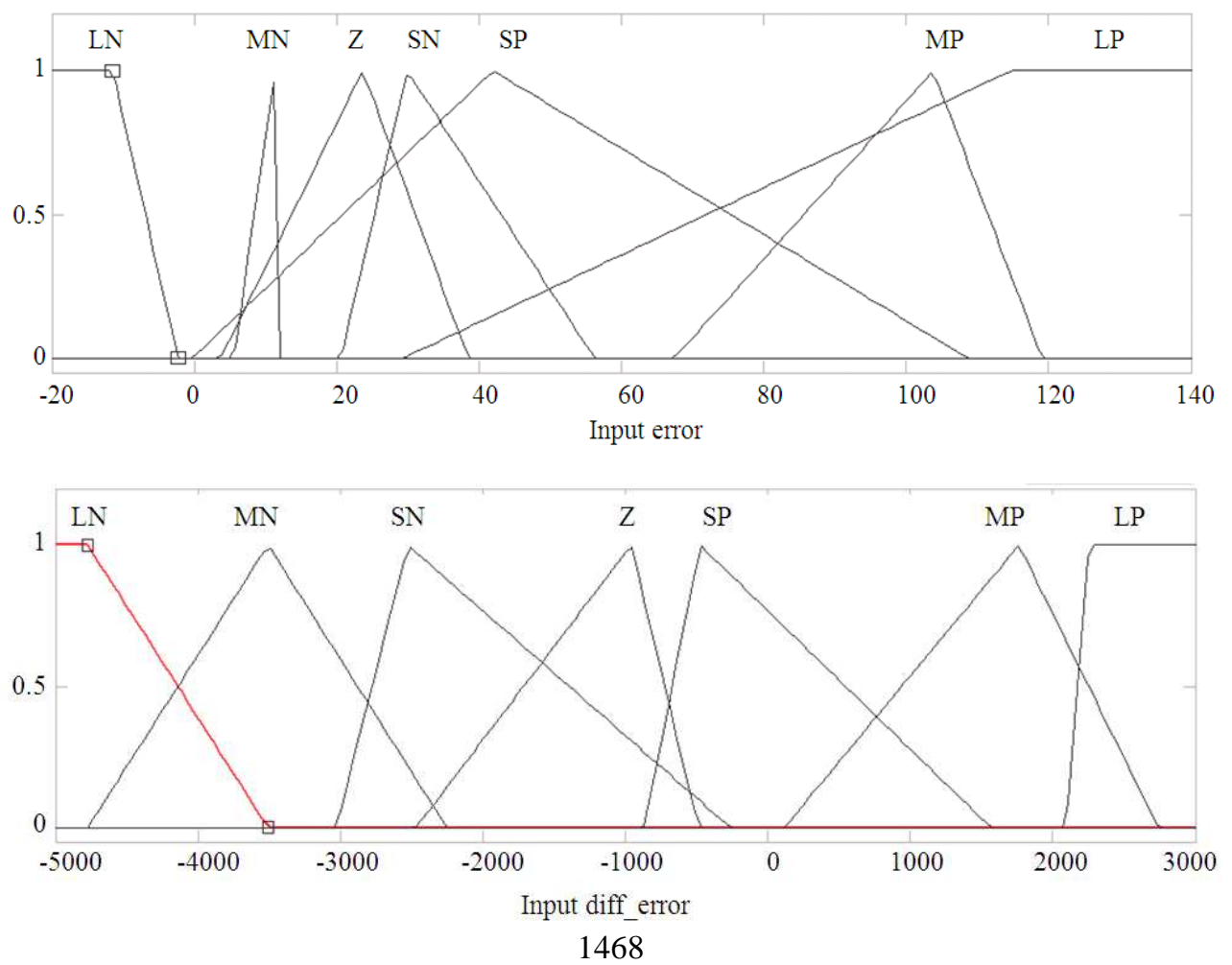
Am. J. Applied Sci., 9 (9): 1464-1471, 2012

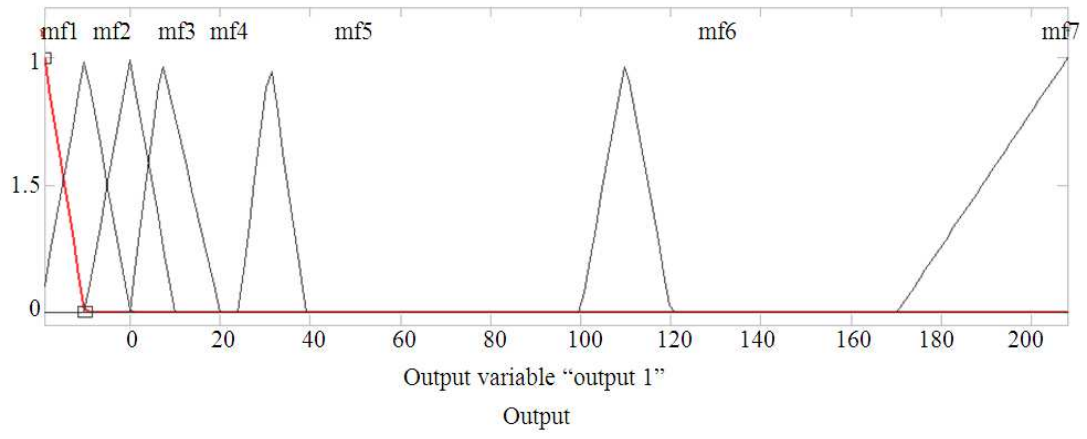

Fig. 3: Optimized memberships function for fuzzy logic controller

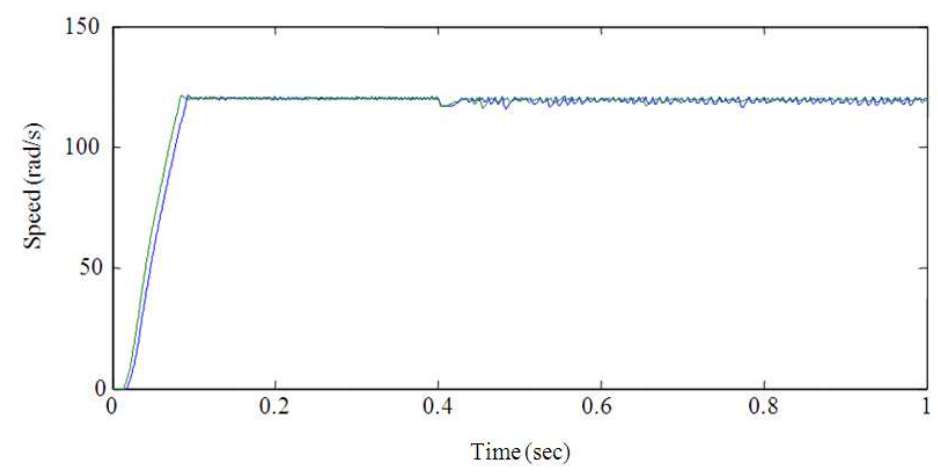

(a)

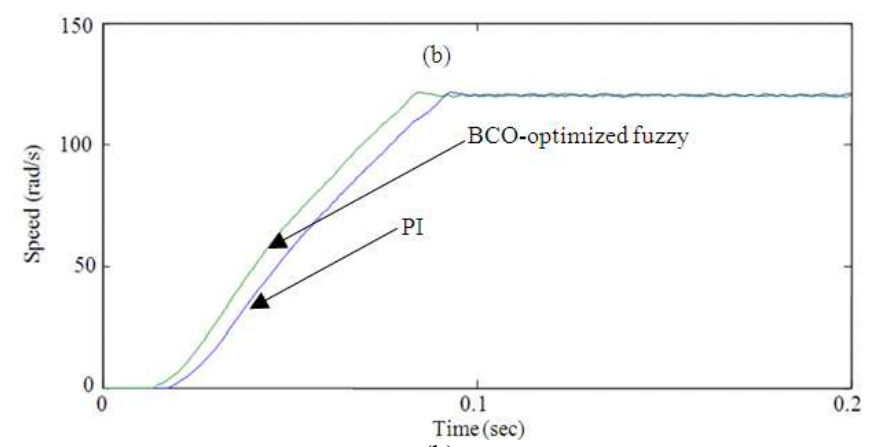

(b)

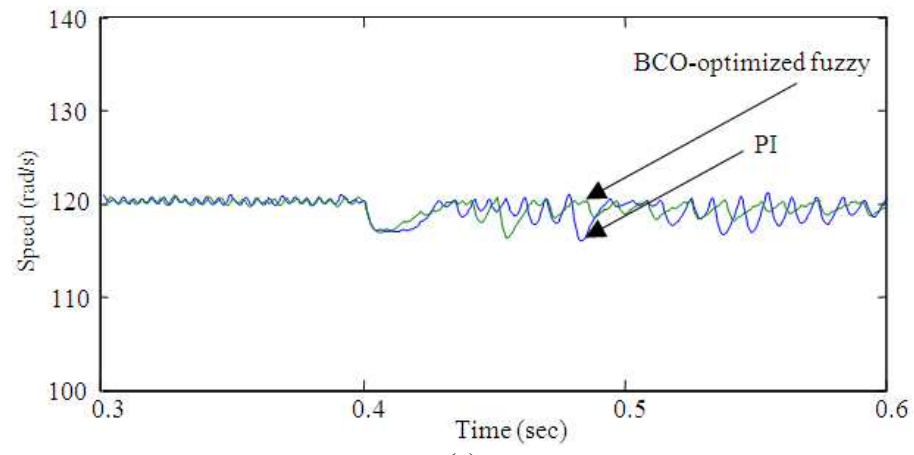

(c)

Fig. 4: (a) Speed response of BCO-optimized fuzzy logic and PI controller, (b) Zoom-in result of (a) during rising time and (c) Zoom-in result of a(a) during load disturbance. 


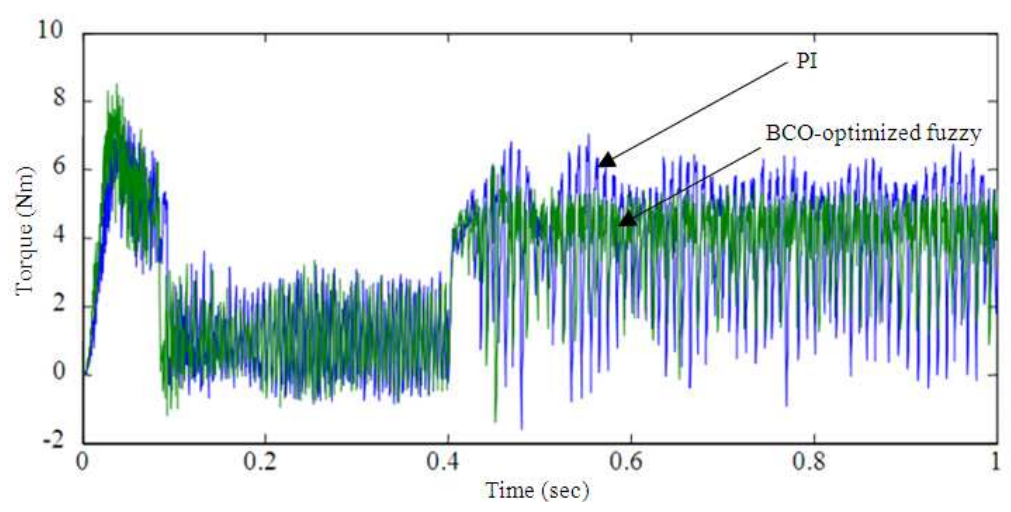

Fig. 5: Torque response of optimized fuzzy logic and PI controller

\section{DISCUSSION}

It could be seen from Fig. 3 that the original membership functions of fuzzy logic controller as depicted in Fig.2 were adjusted to the new locations according to the BCO optimization algorithm. This leads the proposed controller to have faster rise time and settling time and less steady-state error compared to PI controller as shown in Fig. 4(a), (b) and (c). Fig.4(c) focuses on the speed response with variation of load at time of $0.4 \mathrm{sec}$. It was found that both controller could respond to the load disturbance without significant difference, however, the BCO optimized fuzzy controller yields less steady-state speed error. The torque responses of both controller during the step speed command and load variation are similar as depicted in Fig. 5..

\section{CONCLUSION}

In this study, the design technique based on the BCO-optimized fuzzy logic controller of an indirect field-orientated control for the induction motor is presented. Without trial-and-error tuning of the membership functions, the control rules of the fuzzy logic controller are automatically tuned to the optimal values by the BCO. The performances between PI and the proposed controller are compared and it is clear from the simulation results that the proposed BCO optimized fuzzy logic controller yields better speed response than PI controller in terms of rise time and settling time and steady-state error. Both controllers could maintain the speed response in accordance as the speed command after the load variation with less steady-state error for the BCO optimized fuzzy controller.

\section{ACKNOWLEDGEMENT}

This research is financially supported by 2553 yearly budget of Mahasarakham University.

\section{REFERENCES}

Abadeh, M.S., J. Habibi and E. Soroush, 2008. Induction of fuzzy classification systems using evolutionary ACO-based algorithms. Proceedings of the 1st Asia International Conference on Modelling and Simulation, Mar. 27-30, IEEE Xplore Press, Phuket, pp: 346-351. DOI: 10.1109/AMS.2007.53

Blaschke, F., 1972. The Principle of field orientation as applied to the new transvector closed loop control system for rotating field machines. Siemens Rev., 34: 217-220.

Boldea, I. and S.A. Nasar, 2006. Electric Drives. 2nd Edn., CRC/Taylor and Francis, Boca Raton, Fla., ISBN-10: 0849342201, pp: 544.

Esawi, A. and M.F. Ashby, 2003. Cost estimates to guide pre-selection of processes. Mater. Design, 8: 605-616. DOI: 10.1016/S0261-3069(03)00136-5

Feng, C., E.G. Collins, C. Liu and B. Wang, 2003. Radial error feedback control for bar turning in CNC turning centers. ASME J. Manufact. Sci. Eng., 125: 77-84.

Jones, M.T., 2007. Artificial Intelligence: A Systems Approach. 1st Edn., Jones and Bartlett Learning, ISBN-10: 0977858235, pp: 500.

Jurado, F. and M. Valverde, 2005. Genetic fuzzy control applied to the inverter of solid oxide fuel cell for power quality improvement. Elect. Power Syst. Res., 76: 93-105. DOI: 10.1016/j.epsr.2005.05.007

Karakuzu, C., 2010. Parameter tuning of fuzzy sliding mode controller using particle swarm optimization. Int. J. Innovative Comput. Inform. Control, 6: 4755-4770. 
Krause, P.C., O. Wasynczuk and S.D. Sudhoff, 1995. Analysis of electric machinery. 1st Edn., IEEE Press, New York, ISBN-10: 0780311019, pp: 564.

Lee, Y.W., 2005. A study on the design of speed controller for induction motor using tabu search algorithm. Proceedings of the 9th Russian-Korean International Symposium on Science and Technology, Jun. 26-July 2, IEEE Xplore Press, pp: 818-821. DOI: 10.1109/KORUS.2005.1507912

My, C.A., E.L. Bohez, J. Makhanov, S.S. Munlin and M. Phien et al., 2005. On 5-axis freeform surface machining optimization: Vector field clustering approach: Vector Field Clustering Approach. Int. J. CAD/CAM, 5: 1598-1800.

Ogata, K., 1996. Modern Control Engineering. 3rd Edn., Prentice-Hall, Upper Saddle River, NJ., ISBN-10: 0132273071, pp: 997.
Pham, D.T., A. Ghanbarzadeh, E. Koc, S. Otri and S. Rahim et al., 2006. The bees algorithm-a novel tool for complex optimisation problems. Cardiff University.

Vas, P., 1999. Artificial-Intelligence-Based Electrical Machines and Drives: Application of Fuzzy, Neural, Fuzzy-Neural and Genetic-Algorithmbased Techniques. 1st Edn., Oxford University Press, Oxford, ISBN-10: 019859397X, pp: 656.

Waters, T.F., 1996. Fundamentals of Manufacturing for Engineers. 1st Edn., UCL Press, ISBN-10: 1857283384, pp: 334.

Zadeh, L.A., 1965. Fuzzy sets. Inform. Control, 8: 338353. 